\title{
Quantum-chemical studies of rutile nanoparticles toxicity $I$. Defect-free rod-like model clusters
}

\author{
Martin Breza, Peter Šimon \\ Department of Physical Chemistry, Faculty of Chemical and Food Technology, \\ Slovak University of Technology, Radlinského 9, 81237 Bratislava, Slovak Republic \\ martin.breza@stuba.sk
}

In the memory of Prof. Vojtech Kellö (1919-2007)

\begin{abstract}
Using the semiempirical PM6 method, structures of a rod-like $\left[\mathrm{Ti}_{40} \mathrm{O}_{124} \mathrm{H}_{81}\right]^{7-}$ model cluster and of $\left[\mathrm{Ti}_{40} \mathrm{O}_{124} \mathrm{H}_{81} \mathrm{Cu}\right]^{5-}$ with $\mathrm{Cu}^{2+}$ coordinated at various sites were optimized in order to assess the toxicity of rutile nanoparticles. If the relative toxicity of individual Ti centers in rod-like rutile nanoparticles can be evaluated by the electron density transfer to a $\mathrm{Cu}^{2+}$ probe, its maximal values can be ascribed to the pentacoordinated corner and hexacoordinated edge Ti centers with three $\mathrm{Ti}-\mathrm{OH}$ bonds. However, these centers exhibit the least negative interaction energies which can be compensated by the significantly better accessibility of the corner Ti center compared with that of the remaining ones. Ti centers with the most negative interaction energy parameters exhibit the lowest extent of electron density transfer to a $\mathrm{Cu}^{2+}$ probe. Rutile nanoparticles destruction starts at pentacoordinated Ti face centers.
\end{abstract}

Keywords: protonated rutile nanoparticle, PM6 semiempirical method, Cu(II) probe, electron density transfer, active centers

\section{Introduction}

Nano-sized $\mathrm{TiO}_{2}$ particles can be found in a large number of foods, cosmetics and consumer products. Their nanotoxicity has drawn increasing attention because human body is potentially exposed to this nanomaterial either by inhalation, oral or dermal intake. Numerous studies have attempted to characterize their in vivo biodistribution, clearance and toxicological effects, especially in lungs, liver, kidneys, spleen, brain, lymph nodes, testis, blood and lungs of rats (see e.g. Olmedo et al., 2002; Wang et al., 2007; Fabian et al., 2008; Xie et al., 2011; Wang et al., 2011; Wang et al., 2013; Geraets et al., 2014; Elgrabli et al., 2015).

Rutile is the most stable polymorph of $\mathrm{TiO}_{2}$ at all temperatures exhibiting lower total free energy than the metastable phases of anatase or brookite (Hanaor et al., 2012). Rutile has a tetragonal unit cell (space group P42/mnm) (Diebold, 2003) and its crystals are most commonly observed to exhibit a prismatic or acicular growth habit with preferential orientation along their c-axis, [001] direction. This growth habit is favored as the $\{110\}$ facets of rutile exhibit the lowest surface free energy and are therefore thermodynamically the most stable ones (Hanaor et al, 2012a).

Interaction of water with $\mathrm{TiO}_{2}$ is crucial in many of its practical applications. The rutile (110)-aqueous solution interface structure was measured
(Zhang et al., 2007) in deionized water (DIW) at $25^{\circ} \mathrm{C}$ by the X-ray crystal truncation rod method. Rutile surface consists of a stoichiometric (1:1) surface unit mesh with the surface terminated by bridging oxygen (BO) and terminal oxygen (TO) sites with a mixture of water molecules and hydroxyl groups $(\mathrm{OH})$ occupying the TO sites. An additional hydration layer can be observed above the TO site, having three distinct water adsorption sites each in well-defined vertical and lateral locations. Structural displacements of atoms at the oxide surface are sensitive to the solution composition. Ti atom displacements from their bulk lattice positions, as large as $0.05 \AA$ at the rutile (110)-DIW interface, decay in magnitude into a crystal with significant relaxations that are observable down to the fourth Ti-layer below the surface. A systematic outward shift was observed for $\mathrm{Ti}$ atom locations below the $\mathrm{BO}$ rows, while a systematic inward displacement was found for $\mathrm{Ti}$ atoms below the TO rows. The distance between the surface fivefold $\mathrm{Ti}$ atoms and the oxygen atoms of the TO site is $2.13 \pm 0.03 \AA$ in DIW, suggesting molecular adsorption of water at the TO site to the rutile (110) surface in DIW.

Very recently, scanning tunneling microscopy and surface X-ray diffraction have been used (Hussain et al., 2017) to determine the structure of the rutile (110)-aqueous interface which is comprised of an ordered array of hydroxyl molecules with molecu- 
lar water in the second layer. A combination of data from real-space imaging, spectroscopic measurements and surface X-ray diffraction, with interpretation aided by DFT calculations, implies that the rutile $\mathrm{TiO}_{2}$ (110) surface has terminal hydroxyls in the contact layer. The ideal coverage by terminal $\mathrm{OH}$ groups is half a monolayer, which is decreased to approximately 0.4 monolayers due to absences at domain wall boundaries.

According to Alagona and Ghio (Alagona and Ghio, 2009, 2009a), antioxidant activity of prenylated pterocarpans is related to their copper coordination ability. Based on B3LYP calculations of several complexes with $\mathrm{Cu}^{2+}$ of their low-energy conformers, their metal ion affinity (MIA) values have been determined. In aqueous solutions, the solvent effect dampens the free energy differences and reduces the MIA especially when the ion is extensively exposed to the solvent. Stability order of the species with metals bonded at various coordination sites strongly depends on their position and nature. Spin density of the cation upon ligand coordination becomes negligibly low, whereas the ligand spin density approaches 1 . Thus, the ligand is oxidized to a radical cation (Ligand ${ }^{\bullet+}$ ) while $\mathrm{Cu}(\mathrm{II})$ is reduced to $\mathrm{Cu}(\mathrm{I})$. In agreement with experimental investigations, the higher antioxidant activity of individual compounds and their reaction sites can be assigned to higher MIA values and higher reducing character toward $\mathrm{Cu}(\mathrm{II})$. Antioxidant ability of various sites of hyperjovinol A through their ability to coordinate a $\mathrm{Cu}^{2+}$ ion and reduce it to $\mathrm{Cu}^{+}$was successfully tested by Mammino (Mammino, 2013). Another modification of the above-mentioned method has been used for both N centers of a series of para-phenylene diamine (PPD) antioxidants (Puškárová and Breza, 2016). Nearly linear dependence of the experimental antioxidant effectiveness on $\mathrm{Cu}(\mathrm{II})-\mathrm{PPD}$ interaction energies, $\mathrm{Cu}$ atomic charges and other electron density parameters has been deduced.

From the chemical point of view, nanoparticles toxicity is also based on electron density transfer to human tissues. Therefore, the above-mentioned method, tested for antioxidants, might be suitable for the relative toxicity estimation of various sites of model nanoparticles. The liquids in human body are, in principle, aqueous solutions, which implies protonation of the negative charged surface of rutile nanoparticles. For the sake of simplicity, only hexacoordinated Ti atoms and full protonation of non-bridging $\mathrm{O}$ atoms are considered in model systems. Molecular mechanics methods are suitable for large model systems but reveal on their electron structure. DFT methods bring valuable information on electron distribution within the studied systems but their size is significantly restricted due to technical reasons. Semiempirical methods of quantum chemistry seem to be a suitable compromise between the above-mentioned ones. The aim of this study was to estimate the toxicity of various sites of an idealized protonated rod-like rutile nanoparticle (over 200 atoms) based on its $\mathrm{Cu}(\mathrm{II})$ complexation ability and electron density transfer to $\mathrm{Cu}$ at semiempirical PM6 level of theory.

\section{Method}

Geometries of the model systems under study were optimized using the PM6 method of quantum chemistry (Stewart, 2007). Stability of the optimized structures was confirmed by vibrational analysis (no imaginary vibrations). Atomic charges were evaluated in terms of the Mulliken population analysis (MPA) (Mulliken, 1955) and alternatively atomic polar tensor (APT) derived charges (Stephens et al., 1990). All calculations were performed using the Gaussian09 program package (Frisch et al., 2009). Metal-ligand interaction energy $\Delta_{\text {int }} E$ is defined as

$$
\Delta_{\text {int }} E=E_{\text {Complex }}-E_{\mathrm{L}}-E_{\text {ion }}
$$

where $E_{\text {Complex }}$ and $E_{\mathrm{L}}$ are the energies of the ${ }^{2}[\mathrm{~L} \cdots \mathrm{Cu}]^{q+2}$ complex and of the isolated rutile nanoparticle ${ }^{1} \mathrm{~L}^{\mathrm{q}}$ model cluster in their optimized geometries, respectively, and $\mathrm{E}_{\mathrm{ion}}$ is the energy of the isolated ${ }^{2} \mathrm{Cu}^{2+}$ ion (Alagona and Ghio, 2009, 2009a; Mammino, 2013). Left superscripts denote spin multiplicities. Analogously, metal-ligand interaction enthalpy $\Delta_{\text {int }} H_{298}$ and Gibbs free energy $\Delta_{\text {int }} G_{298}$ at $298 \mathrm{~K}$ data were also evaluated.

Deformation energy $E_{\text {def }}$ is the difference (Alagona and Ghio, 2009, 2009a; Mammino, 2013) between the energy of the ligand $\mathrm{L}^{\mathrm{q}}$ in its ${ }^{2}[\mathrm{~L} \cdot \mathrm{Cu}]^{\mathrm{q}+2}$ complex geometry $\left(E_{\mathrm{L}(\mathrm{Cu})}\right)$ and that corresponding to its optimized structure $\left(E_{\mathrm{L}}\right)$

$$
E_{\mathrm{def}}=E_{\mathrm{L}(\mathrm{Cu})}-E_{\mathrm{L}}
$$

Deformation energies should be lower than the corresponding metal-ligand ones.

\section{Results and Discussion}

Using experimental rutile structure (Swope et al., 1995), an idealized rod-like $\left[\mathrm{Ti}_{40} \mathrm{O}_{124}\right]^{88-}$ cluster (Fig. 1) of ca $1.5 \mathrm{~nm} \times 1 \mathrm{~nm} \times 1 \mathrm{~nm}$ size was formed. Its planes are parallel with the (110) plane of the rutile unit cell and all $\mathrm{Ti}$ atoms are hexacoordinated. As such a highly negative nanoparticle cannot exist in biological aqueous solutions, all monovalent $\mathrm{O}$ atoms were protonated to form a $\left[\mathrm{Ti}_{40} \mathrm{O}_{124} \mathrm{H}_{81}\right]^{7-}$ cluster with geometry optimized 


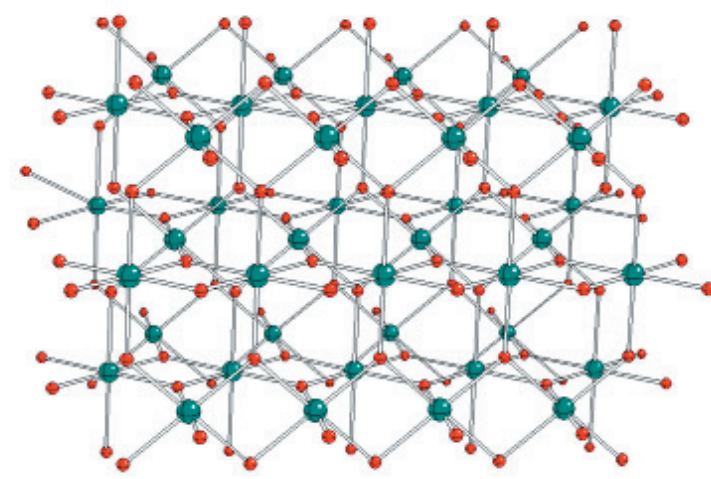

Fig. 1. $\left[\mathrm{Ti}_{40} \mathrm{O}_{124}\right]^{88-}$ cluster in experimental rutile geometry (Swope et al., 1995), ( $\mathrm{Ti}$ - green, $\mathrm{O}-\mathrm{red}$ ).

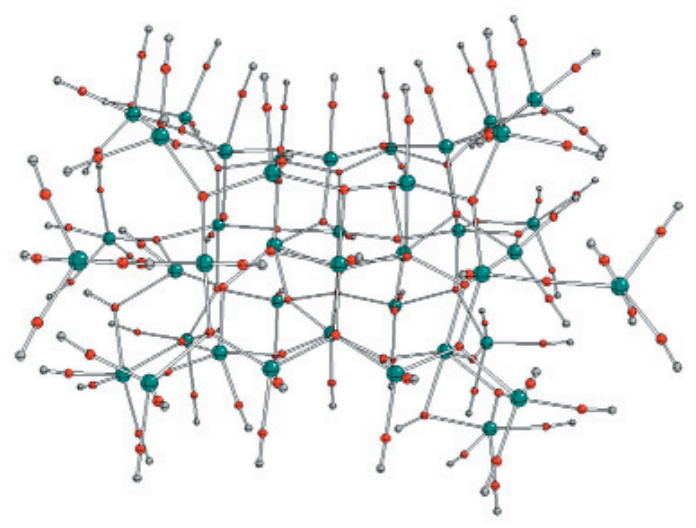

Fig. 2. PM6 optimized geometry of $\left[\mathrm{Ti}_{40} \mathrm{O}_{124} \mathrm{H}_{81}\right]^{7-}$ cluster ( $\mathrm{Ti}$ - green, $\mathrm{O}$ - red, $\mathrm{H}-$ grey).

in the singlet ground spin state (Fig. 2). It can be seen that its planes are significantly deformed due to protonation and the original Ti hexacoordination is sometimes reduced to pentacoordination. Several Ti centers can be distinguished according to their bonding to hydroxyl groups $(\mathrm{OH})$ and bridging oxygens $\left(\mathrm{O}_{\mathrm{b}}\right)$ between two Ti atoms. These centers can be divided into three groups as follows:
A. At the rod corners, only pentacoordinated $\mathrm{Ti}(\mathrm{OH})_{3}\left(\mathrm{O}_{\mathrm{b}}\right)_{2}$ centers are found (model A, see Fig. 3)

B. Rod edges contain either hexacoordinated $\mathrm{Ti}(\mathrm{OH})_{3}\left(\mathrm{O}_{\mathrm{b}}\right)_{3}($ model B 1 , see Fig. 4$)$, $\mathrm{Ti}(\mathrm{OH})_{2}\left(\mathrm{O}_{\mathrm{b}}\right)_{4}$ (model B2, see Fig. 4) and $\mathrm{Ti}(\mathrm{OH})\left(\mathrm{O}_{\mathrm{b}}\right)_{5}$ (model B3, see Fig. 4) centers or pentacoordinated $\mathrm{Ti}(\mathrm{OH})_{4}\left(\mathrm{O}_{\mathrm{b}}\right)$ (model B4, see Fig. 5), $\mathrm{Ti}(\mathrm{OH})_{3}\left(\mathrm{O}_{\mathrm{b}}\right)_{2}$ (model B5, see Fig. 5) and $\mathrm{Ti}(\mathrm{OH})_{2}\left(\mathrm{O}_{\mathrm{b}}\right)_{3}$ (model B6, see Fig. 5) centers.

C. Rod faces have hexacoordinated $\mathrm{Ti}(\mathrm{OH})\left(\mathrm{O}_{\mathrm{b}}\right)_{5}$ (model C1, see Fig. 6) or pentacoordinated $\mathrm{Ti}(\mathrm{OH})\left(\mathrm{O}_{\mathrm{b}}\right)_{4}$ (model C2, see Fig. 6) centers.

In order to compare the reactivity of all the abovementioned possible reaction sites, a $\mathrm{Cu}^{2+}$ ion was added at the distance of ca 1.9-2.3 $\AA$ from the hydroxyl groups of every center under study. Geometries of thus created $\left[\mathrm{Ti}_{40} \mathrm{O}_{124} \mathrm{H}_{81} \mathrm{Cu}\right]^{5-}$ clusters were again PM6 optimized in the ground doublet spin state. The resulting structures are depicted in Figs. 3-6. For the sake of simplicity, notation of the above reaction sites agrees with the $\left[\mathrm{Ti}_{40} \mathrm{O}_{124} \mathrm{H}_{81} \mathrm{Cu}\right]^{5-}$

Tab. 1. Copper(II)-ligand interaction energies $\left(\Delta_{\text {int }} E\right)$, Gibbs free interaction energies $\left(\Delta_{\text {int }} G_{298}\right)$ and interaction enthalpies $\left(\Delta_{\text {int }} H_{298}\right)$ at $298 \mathrm{~K}$, and deformation energies $\left(E_{\text {def }}\right)$ of ${ }^{2}\left[\mathrm{Ti}_{40} \mathrm{O}_{124} \mathrm{H}_{81} \mathrm{Cu}\right]^{5-}$ structures obtained by the PM6 method for the model systems under study (see Appendix).

\begin{tabular}{lcccc}
\hline Model & $\begin{array}{c}\Delta_{\text {int }} E \\
{[\mathrm{~kJ} / \mathrm{mol}]}\end{array}$ & $\begin{array}{c}\Delta_{\text {int }} G_{298} \\
{[\mathrm{~kJ} / \mathrm{mol}]}\end{array}$ & $\begin{array}{c}\Delta_{\text {int }} H_{298} \\
\mathrm{~kJ} / \mathrm{mol}]\end{array}$ & $\begin{array}{c}E_{\text {def }} \\
{[\mathrm{kJ} / \mathrm{mol}]}\end{array}$ \\
\hline A & -3789.9 & -3707.4 & -3770.6 & 1212.9 \\
B1 & -3888.6 & -3803.7 & -3862.7 & 1196.2 \\
B2 & -4046.8 & -3955.1 & -4019.2 & 1312.5 \\
B3 & -4190.3 & -4110.8 & -4167.3 & 1397.9 \\
B4 & -4086.5 & -3993.6 & -4058.5 & 1353.9 \\
B5 & -4047.2 & -3950.1 & -4022.9 & 1331.3 \\
B6 & -3981.1 & -3888.2 & -3956.8 & 1392.4 \\
C1 & -4053.0 & -3964.8 & -4029.2 & 1438.0 \\
C2 & -4152.6 & -4057.6 & -4126.7 & 1392.4 \\
\hline
\end{tabular}

Tab. 2. $\mathrm{MPA}\left(q(\mathrm{Cu})_{\mathrm{MPA}}\right)$ and APT $\left(q(\mathrm{Cu})_{\mathrm{APT}}\right)$ copper atomic charges and lengths of $\mathrm{Cu}-\mathrm{O}$ bond to hydroxyl $\left(d_{\mathrm{Cu}-\mathrm{OH}}\right)$ and bridging $\left(d_{\mathrm{Cu}-\mathrm{Ob}}\right)$ oxygen atoms of ${ }^{2}\left[\mathrm{Ti}_{40} \mathrm{O}_{124} \mathrm{H}_{81} \mathrm{Cu}\right]^{5-}$ structures obtained by the PM6 method for the model systems under study.

\begin{tabular}{|c|c|c|c|c|}
\hline Model & $q(\mathrm{Cu})_{\mathrm{MPA}}$ & $q(\mathrm{Cu})_{\mathrm{APT}}$ & $d_{\mathrm{Cu}-\mathrm{OH}}[\AA]^{\mathrm{a})}$ & $d_{\mathrm{Cu}-\mathrm{Ob}}[\AA]$ \\
\hline A & 0.586 & 0.669 & $2.009,2.038,2.048(2.032)$ & - \\
\hline B1 & 0.585 & 0.638 & $2.018,2.034,2.039(2.030)$ & - \\
\hline B2 & 0.633 & 0.721 & $2.068,2.077,2.086(2.077)$ & - \\
\hline B3 & 0.648 & 0.744 & $2.089,2.124,2.126,2.184(2.131)$ & - \\
\hline B4 & 0.634 & 0.734 & $2.040,2.058,2.062,2.105(2.066)$ & - \\
\hline B5 & 0.648 & 0.721 & $2.126,2.130,2.138,2.160,2.193(2.149)$ & - \\
\hline B6 & 0.645 & 0.740 & $2.133,2.139,2.158,2.198(2.157)$ & 2.107 \\
\hline C1 & 0.627 & 0.739 & $2.081,2.120,2.137,2.152(2.123)$ & 2.146 \\
\hline $\mathrm{C} 2$ & 0.641 & 0.899 & $2.141,2.177,2.194,2.256,2.294(2.212)$ & 2.071 \\
\hline
\end{tabular}

a) Average values in parentheses. 
model system labels. Their selected characteristics are presented in Tables 1 and 2 and in Table 3 of Appendix.

Our results (Table 1) indicate that all copper(II)-ligand interaction energy parameters exhibit the same trends. Differences between various model systems are higher than those in the corresponding deformation energies. Thus, no corrections in the observed trends of the calculated interaction energy are necessary. As expected, corner Ti centers (model A) exhibited the least negative interaction energy parameters. The most negative values were observed for the hexacoordinated edge $\mathrm{Ti}$ centers with a single hydroxyl group (model B3). These are shifted to less negative values with the increasing number of hydroxyl groups in other hexacoodinated edge Ti centers (B2 and B1 models). Pentacoordinated edge Ti centers (B4, B5 and B6 models) exhibited reverse trends. Interaction energy parameters of hexacoordinated face Ti centers (C1 model) are comparable with the medians of the edge Ti centers. Their values for pentacoodinated face $\mathrm{Ti}$ centers (C2 model) are significantly more negative due to the removal of the $\left[\mathrm{Ti}(\mathrm{OH})_{5}\right]^{-}$cluster from the nanoparticle by a $\mathrm{Cu}^{2+}$ probe, which indicates the most probable site of a nanoparticle destruction.

Table 2 contains charges of $\mathrm{Cu}$ probes indicating the extent of electron density transfer from the ligand (the higher $\mathrm{Cu}$ charge corresponds to the lower electron density transfer). The resulting $\mathrm{Cu}$ spin density is negligible in all the model systems under study and thus the corresponding data are not presented. Positive APT charges at $\mathrm{Cu}$ atoms are higher than the MPA ones and need not exhibit the same trends for pentacoordinated centers. In general, more negative interaction energy parameters (Table 1) are connected with

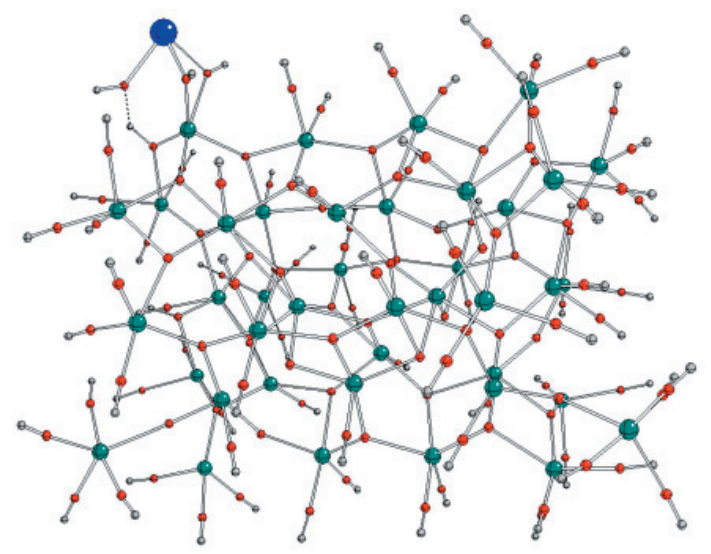

Fig. 3. PM6 optimized geometry of $\left[\mathrm{Ti}_{40} \mathrm{O}_{124} \mathrm{H}_{81} \mathrm{Cu}\right]^{5-}$ cluster, model A ( $\mathrm{Ti}$ - green, $\mathrm{O}$ - red, $\mathrm{H}$ - grey, $\mathrm{Cu}$ - blue). higher $\mathrm{Cu}$ charges, however they are significantly affected by the number and type of $\mathrm{Cu}$ bonded oxygen atoms $\left(\mathrm{OH}\right.$ or $\left.\mathrm{O}_{\mathrm{b}}\right)$. $\mathrm{Cu}$ probes in $\mathrm{A}, \mathrm{B} 1$ and B2 models are tricoordinated, in B3 and B4 models tetracoordinated and in the $\mathrm{B} 5$ one, they

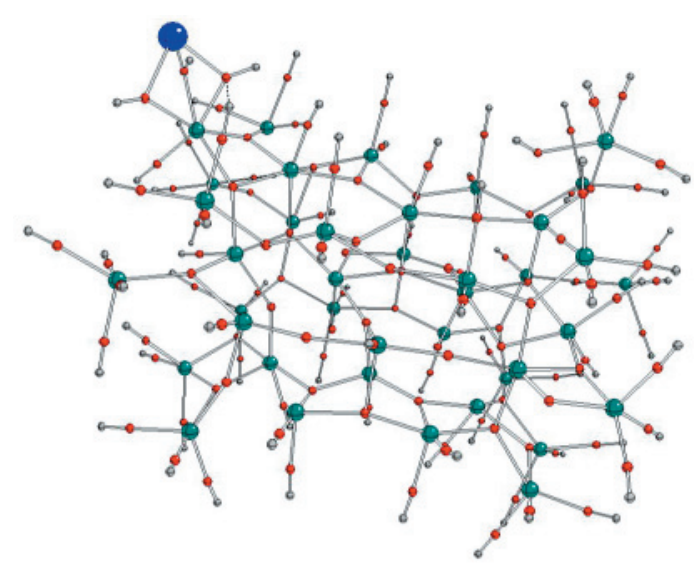

Model B1

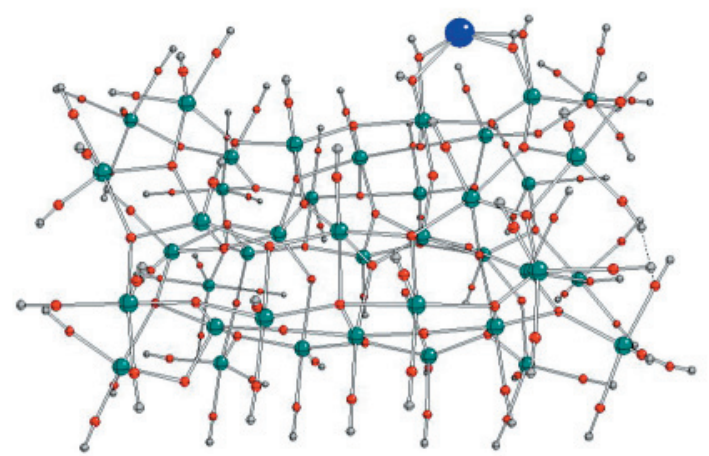

Model B2

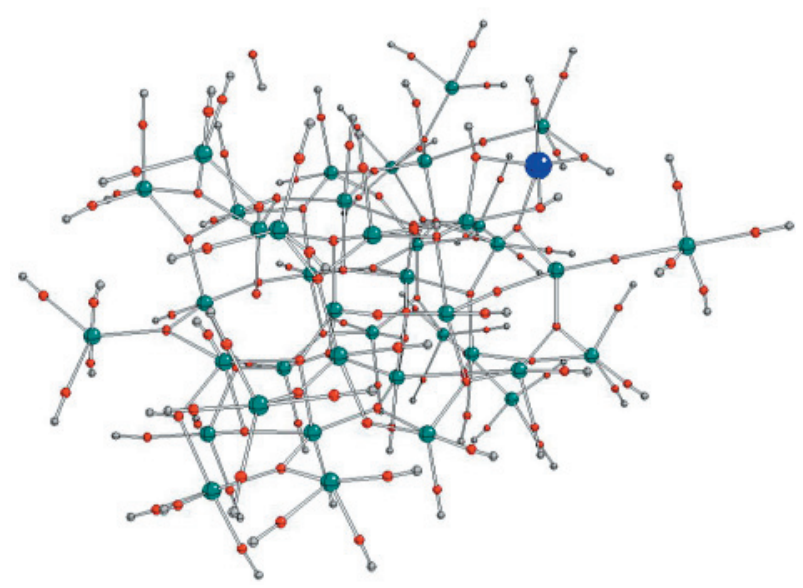

Model B3

Fig. 4. PM6 optimized geometry of $\left[\mathrm{Ti}_{40} \mathrm{O}_{124} \mathrm{H}_{81} \mathrm{Cu}\right]^{5-}$ clusters, models B 1-B3 (see Fig. 3 for atom notations). 
are pentacoordinated by hydroxyls. The remaining models: B6, C1 and C2, have the $\mathrm{Cu}$ probe coordinated by a single bridging oxygen atom and 4-5 hydroxyls which can lead to irregularities in $\mathrm{Cu}$ charge. Average $\mathrm{Cu}-\mathrm{OH}$ bond lengths (as a

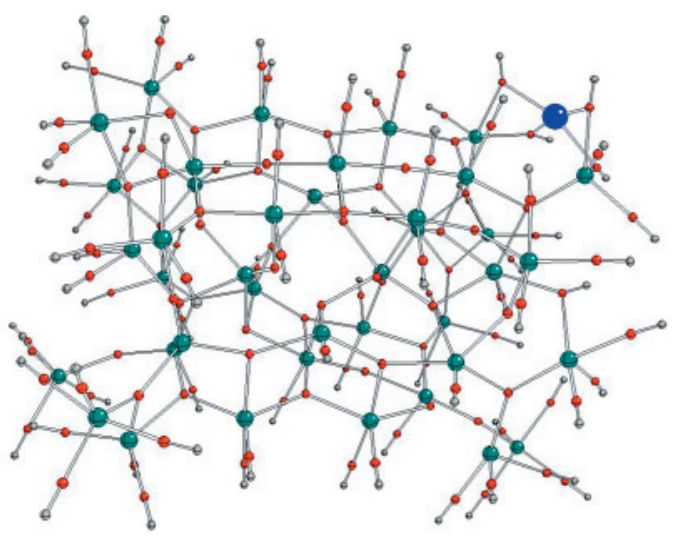

\section{Model B4}

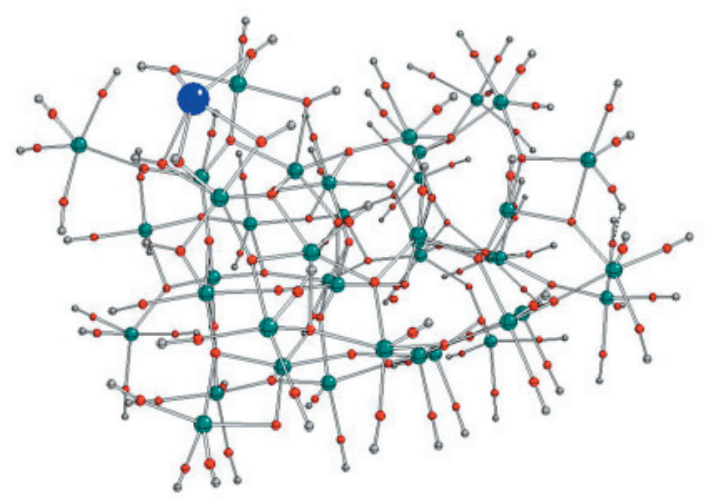

Model B5

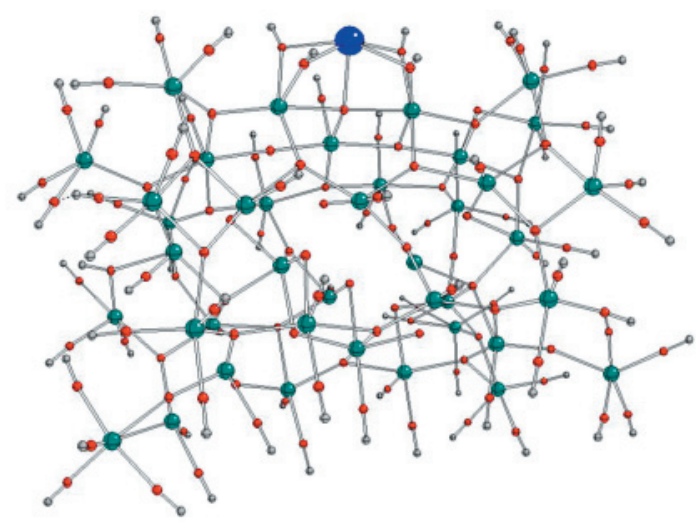

Model B6

Fig. 5. PM6 optimized geometry of $\left[\mathrm{Ti}_{40} \mathrm{O}_{124} \mathrm{H}_{81} \mathrm{Cu}\right]^{5-}$ clusters, models B4-B6 (see Fig. 3 for atom notations). measure of corresponding $\mathrm{Cu}-\mathrm{O}$ bond strengths implied by electron density transfer) follow the trends in the interaction energy parameters and Cu charges for hexacoordinated Ti edge centers unlike the pentacoordinated ones.

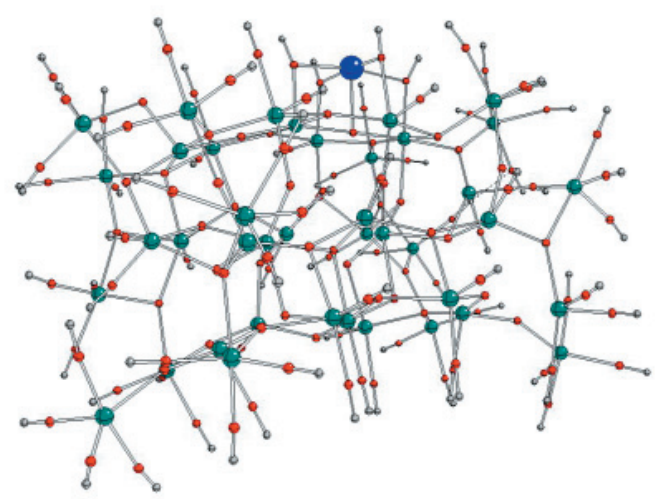

Model C1

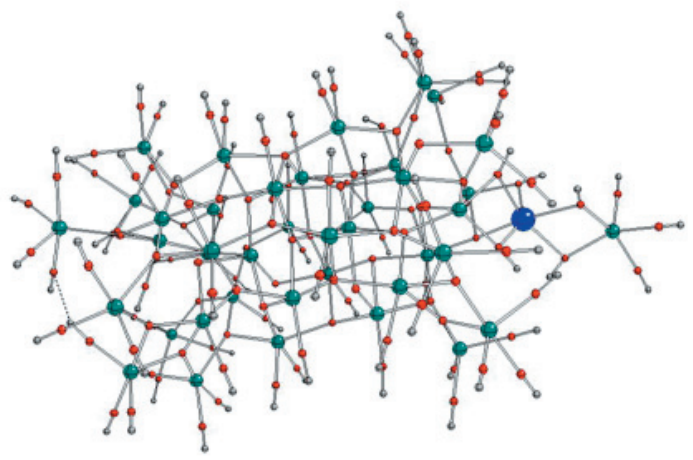

\section{Model C2}

Fig. 6. PM6 optimized geometry of $\left[\mathrm{Ti}_{40} \mathrm{O}_{124} \mathrm{H}_{81} \mathrm{Cu}\right]^{5-}$ clusters, models $\mathrm{C} 1$ and $\mathrm{C} 2$ (see Fig. 3 for atom notations).

\section{Conclusions}

If relative toxicity of individual $\mathrm{Ti}$ centers in rod-like rutile nanoparticles can be evaluated by the electron density transfer to a $\mathrm{Cu}^{2+}$ probe, its maximal values can be ascribed to the pentacoordinated corner (A model) and hexacoordinated edge Ti centers with three $\mathrm{Ti}-\mathrm{OH}$ bonds (B1 model). However, these centers exhibit the least negative interaction energies, which can be compensated by the significantly better accessibility of the corner $\mathrm{Ti}$ center (A model) compared with that of the remaining ones. Ti centers with the most negative interaction energy parameters exhibit the lowest extent of electron density transfer to a $\mathrm{Cu}^{2+}$ probe (B3 and $\mathrm{C} 2$ 
models). Rutile nanoparticles destruction starts at pentacoordinated Ti face centers (C2 model).

Our model systems consist of three $\mathrm{TiO}_{2}$ planes only and their protonation causes too high planes warping in comparison with significantly larger real systems. As quantum-chemical calculations of larger model systems are connected with serious technical problems even at the semiempirical level of theory, ONIOM treatment (Dapprich et al., 1999) combining semiempirical and molecular mechanics calculations should be used. Molecular mechanics methods enable to increase the size of model systems (which in our case reduces the plane warping due to surface protonation) but do not reveal their electron structure.

It has to be mentioned that our quantum-chemical treatment evaluates the electron affinity of individual surface reaction sites as the source of their toxicity (and, in general, of the oxidation stress). On the other hand, the experiments measure an integral response reflecting the microstructure properties of nanoparticles as a whole. In our future studies, the above-mentioned conclusions on toxicity of individual Ti centers in rutile nanoparticles will be extended to model systems of various shapes and sizes in order to identify their surface reaction sites. In the next step, nanoparticles of suitable shapes should be synthesized. This will subsequently enable studying in vitro correlations between theoretical and experimental data based on quantitative structure - activity relationship models.

\section{Acknowledgements}

This project has received funding from the European Union's Horizon 2020 research and innovation programme under grant agreement No 685817 (HISENTS). The authors thank the HPC center at the Slovak University of Technology in Bratislava, which is a part of the Slovak Infrastructure of High Performance Computing (SIVVP Project ITMS 26230120002, funded by the European Region Development Funds) for providing computing facilities. The authors also appreciate the Ministry of Education, Science, Research and Sport of the Slovak Republic for funding within the scheme 'Excellent research teams'.

\section{References}

Alagona G, Ghio C (2009) Antioxidant Properties of Pterocarpans through Their Copper(II) Coordination Ability. A DFT Study in Vacuo and in Aqueous Solution. J Phys Chem. A 113: 15206-15216.

Alagona G, Ghio C (2009a) Plicatin B conformational landscape and affinity to copper (I and II) metal cations. A DFT study. Phys Chem Chem Phys 11: 776-790.

Dapprich S, Komáromi I, Byun KS, Morokuma K, Frisch MJ (1999) A New ONIOM Implementation in Gaussian 98. 1. The Calculation of Energies, Gradients and Vibrational Frequencies and Electric Field Derivatives. J Mol Struct (Theochem) 462: 1-21.

Diebold U (2003) The surface science of titanium dioxide. Surf Sci Rep 48: 53-229.

Elgrabli D, Beaudouin R, Jbilou N, Floriani M, Pery A, Rogerieux F, Lacroix G (2015) Biodistribution and Clearance of $\mathrm{TiO}_{2}$ Nanoparticles in Rats after Intravenous Injection. PLoS ONE 10: e0124490.

Fabian E, Landsiedel R, Ma-Hock L, Wiench K, Wohlleben W, van Ravenzwaay B (2008) Tissue distribution and toxicity of intravenously administered titanium dioxide nanoparticles in rats. Arch Toxicol 82: $151-157$.

Frisch MJ, Trucks GW, Schlegel HB, Scuseria GE, Robb MA, Cheeseman JR et al. (2009) Gaussian 09, Revision D.01, Gaussian Inc., Wallingford, CT.

\section{Appendix. Calculated energy terms in Table 3.}

Tab. 3. Energies $(E)$, Gibbs free energies $\left(G_{298}\right)$ and enthalpies $\left(H_{298}\right)$ at $298 \mathrm{~K}$ of the optimized structures and energies $\left(E_{\mathrm{L}(\mathrm{Cu})}\right)$ of ${ }^{1}\left[\mathrm{Ti}_{40} \mathrm{O}_{124} \mathrm{H}_{81}\right]^{7-}$ structures in the optimized geometries of ${ }^{2}\left[\mathrm{Ti}_{40} \mathrm{O}_{124} \mathrm{H}_{81} \mathrm{Cu}\right]^{5-}$ structures obtained by the PM6 method for the model systems under study (model system charges as right superscripts) in the lowest spin states (spin multiplicities as left superscripts).

\begin{tabular}{lccccc}
\hline Compound & Model & $E[$ hartree $]$ & $G_{298}$ [hartree $]$ & $H_{298}$ [hartree $]$ & $E_{\mathrm{L}(\mathrm{Cu})}[$ hartree $]$ \\
\hline${ }^{2} \mathrm{Cu}^{2+}$ & - & 1.12549 & 1.10898 & 1.12785 & - \\
${ }^{1}\left[\mathrm{Ti}_{40} \mathrm{O}_{124} \mathrm{H}_{81}\right]^{7-}$ & - & -16.76540 & -16.06479 & -15.48855 & - \\
${ }^{2}\left[\mathrm{Ti}_{40} \mathrm{O}_{124} \mathrm{H}_{81} \mathrm{Cu}\right]^{5-}$ & A & -17.08336 & -16.36790 & -15.79679 & -16.62130 \\
& B1 & -17.12093 & -16.40457 & -15.83200 & -16.66530 \\
& B2 & -17.18115 & -16.46220 & -15.89152 & -16.68130 \\
& B3 & -17.23596 & -16.52159 & -15.94788 & -16.70352 \\
& B4 & -17.19641 & -16.47689 & -15.90647 & -16.68078 \\
& B5 & -17.18140 & -16.4603 & -15.89300 & -16.67434 \\
& B6 & -17.15617 & -16.43676 & -15.86785 & -16.62577 \\
& C1 & -17.18356 & -16.46588 & -15.89537 & -16.63582 \\
C2 & -17.22160 & -16.5012 & -15.93244 & -16.69118 \\
\hline
\end{tabular}

Energy, Gibbs free energy and enthalpy of ${ }^{2} \mathrm{Cu}^{2+}$ correspond to $E_{\text {ion }}$ in Eq. (1). Analogous data of ${ }^{1}\left[\mathrm{Ti}_{40} \mathrm{O}_{124} \mathrm{H}_{81}\right]^{7-}$ correspond to $E_{\mathrm{L}}$ in Eqs. (1) and (2). Energies, Gibbs free energies and enthalpies of ${ }^{2}\left[\mathrm{Ti}_{40} \mathrm{O}_{124} \mathrm{H}_{81} \mathrm{Cu}\right]^{5-}$ correspond to $E_{\text {Complex }}$ in Eq. (1). 
Geraets L, Oomen AG, Krystek P, Jacobsen NR, Wallin H, Laurentie $\mathrm{M}$ et al. (2014) Tissue distribution and elimination after oral and intravenous administration of different titanium dioxide nanoparticles in rats. Part Fibre Toxicol 11: 0030.

Hanaor DAH, Assadi MHN, Li S, Yu A, Sorrell CC (2012) Ab initio study of phase stability in doped $\mathrm{TiO}_{2}$. Comput Mechan 50: 185-94.

Hanaor DAH, Xu W-Q, Ferry M, Sorrell CC (2012a) Abnormal grain growth of rutile $\mathrm{TiO}_{2}$ induced by $\mathrm{ZrSiO}_{4}$. J Cryst Growth 359: 83-91.

Hussain H, Tocci G, Woolcot T, Torrelles X, Pang CL, Humphrey DS, Yim CM, Grinter DC, Cabail G, Bikondo O, Lindsay R, Zegenhagen J, Michaelides A, Thornton G (2017) Structure of a model $\mathrm{TiO}_{2}$ photocatalytic interface. Nature Mater 16: 461-466.

Mammino L (2013) Investigation of the antioxidant properties of hyperjovinol A through its $\mathrm{Cu}(\mathrm{II})$ coordination ability. J Mol Model 19: 2127-2142.

Mulliken RS (1955) Electronic Population Analysis on LCAO-MO Molecular Wave Functions. I. J Chem Phys 23: 1833-1840.

Olmedo D, Guglielmotti MB, Cabrini RL (2002) An experimental study of the dissemination of Titanium and Zirconium in the body. J Mater Sci-Mater Medicine 13: 793-796.

Wang JX, Zhou GQ, Chen CY, Yu HW, Wang TC, Ma YM et al. (2007) Acute toxicity and biodistribution of different sized titanium dioxide particles in mice after oral administration. Toxicol Let 168: 176-185.
Puškárová I. Breza M (2016) DFT studies of the effectiveness of p-phenylenediamine antioxidants through their $\mathrm{Cu}(\mathrm{II})$ coordination ability. Polym Degrad Stab 128: 15-21.

Stephens PJ, Jalkanen KJ, Kawiecki RW (1990) Theory of vibrational rotational strengths: comparison of a priori theory and approximate models. J Am Chem Soc 112: 6518-6529.

Stewart JJP (2007) Optimization of parameters for semiempirical methods. V. Modification of NDDO approximations and application to 70 elements. J Mol Model 13: 1173-1213.

Swope RJ, Smyth JR, Larson AC (1995) H in rutiletype compounds: I. Single-crystal neutron and X-ray diffraction study of $\mathrm{H}$ in rutile. Am Mineral 80: 448-453.

Wang Y, Chen Z, Ba T, Pu J, Chen T, Song Y et al. (2013) Susceptibility of young and adult rats to the oral toxicity of titanium dioxide nanoparticles. Small 9: $1742-1752$.

Xie G, Wang C, Zhong G (2011) Tissue distribution and excretion of intravenously administered titanium dioxide nanoparticles. Toxicol Let 205: 55-61.

Zhang Z, Fenter P, Sturchio NC, Bedzyk MJ, Machesky M, Wesolowski DJ (2007) Structure of rutile $\mathrm{TiO}_{2}$ (110) in water and 1 molal $\mathrm{Rb}^{+}$at $\mathrm{pH}$ 12: Inter-relationship among surface charge, interfacial hydration structure, and substrate structural displacements. Surf Sci 601: 1129-1143. 